\title{
Saxra (diablo) / Pachamama; Música, tejido, calendario e identidad entre los jalq'a
}

GABRIEL MARTíNEZ

\section{RESUMEN}

Se explora el proceso creador de identidad entre la población indígena de habla quechua denominada jalq'a, radicada en la frontera entre los Departamentos de Chuquisaca y Potosí en Bolivia, examinando aquellas estructuras de pensamiento que nos pueden revelar la música, los tejidos y el discurso religioso. En primer lugar, se trata de desentrañar las relaciones internas que hay entre el discurso religioso y la música en los jalq'a, a partir del calendario de fiestas y, secundariamente, entre el discurso religioso y los tejidos de los jalq'a. Se intentan comprender, por lo tanto, las relaciones semióticas íntimas que hay entre estos lenguajes, que aparecen tan entrelazados: cómo se interrelacionan, cómo se articulan y se distribuyen los papeles para la construcción de una significación -la del calendario. Ello, de manera inevitable, nos llevará a enfrentar problemas semióticos no resueltos del discurso religioso andino, cuyas soluciones esbozaremos sólo a título de hipótesis de trabajo.

Palabras claves: Jalq’a - religión - fiesta - música Andes.

\section{ABSTRACT}

Identity creation process is explored among the Jalq'a, a Quechua speaking indigenous population residing in the border of the Departments of Chuquisaca and Potosi in Bolivia, examining thought structures revealed in music, textiles and religious speech. Firstly, we attempt to figure out the internal relationships between Jalq'a religious discourse and music through the festivities' calendar, and secondly, between the former and Jalq'a textiles. Therefore, we try to understand intimate semiotic relationships that seem to be interlocked: how their roles interrelate, articulate and distribute in the construction of a meaning -that of the calendar. This will unavoidably lead us to face unsolved semiotic problems in Andean religious discourse, whose solutions will be only sketched as a work hypothesis.

Key words: Jalq'a - religion - festivity - music - Andes.

\section{Introducción}

Hay aquí, en este Simposio, ${ }^{1}$ un conjunto de tres ponencias que se refieren a los jalq'a, un grupo étnico andino que habita la región centro-sur del macizo montañoso, entre los Departamentos de Chuquisaca y Potosí, en Bolivia. Son las ponencias de Verónica Cereceda, relativa a los tejidos de los jalq'a, de Rosalía Martínez, sobre el Saxra y la música entre los jalq'a, y la mía, sobre las relaciones entre el discurso religioso, la música y los tejidos, también entre los jalq'a.

Ellas representan, de algún modo, un intento muy preliminar aún, de acercamiento al problema de las relaciones entre estos tres lenguajes -música, tejidos y discurso religioso- y los temas de la identidad étnica. Pero dicho intento no responde todavía a una investigación planificada en este sentido y por el momento sólo se mantiene a nivel de trabajos individuales e intercambio de observaciones. Tampoco las ponencias han sido preparadas coordinadamente por sus autores, de modo que, con seguridad, ustedes verán repetirse muchos temas e ideas.

Los jalq'a constituyen un grupo étnico de habla quechua, que se despliega a ambos lados de la frontera entre las provincias de Chayanta, en el Departamento de Potosí, y Oropeza, en el Departamento de Chuquisaca (Figura 1).

Conforman una población cercana a las 26.000 personas, que habitan en punas, cabeceras de valle y valles, cultivando papa, trigo, cebada, maíz, algo de quínoa, arvejas, habas, zapallos, hortalizas y unos pocos frutales en las partes más bajas. Ovejas y cabras, algunos bueyes y burros componen hatos familiares más bien pequeños, formando parte de economías parcelarias muy modestas $\mathrm{y}$ en algunos sectores, paupérrimas.

1 Nota del editor: Este trabajo fue presentado en el Simposio "Cosmología y música en los Andes", efectuado en Berlín en junio de 1995. Fue publicado en el libro "Cosmología y música en los Andes", editado por VERVUERT: Biblioteca Iberoamericana 1996, Madrid (1996). Dado que dicho libro no tuvo difusión en Latinoamérica, Verónica Cereceda autorizó la publicación del artículo en Estudios Atacameños. 


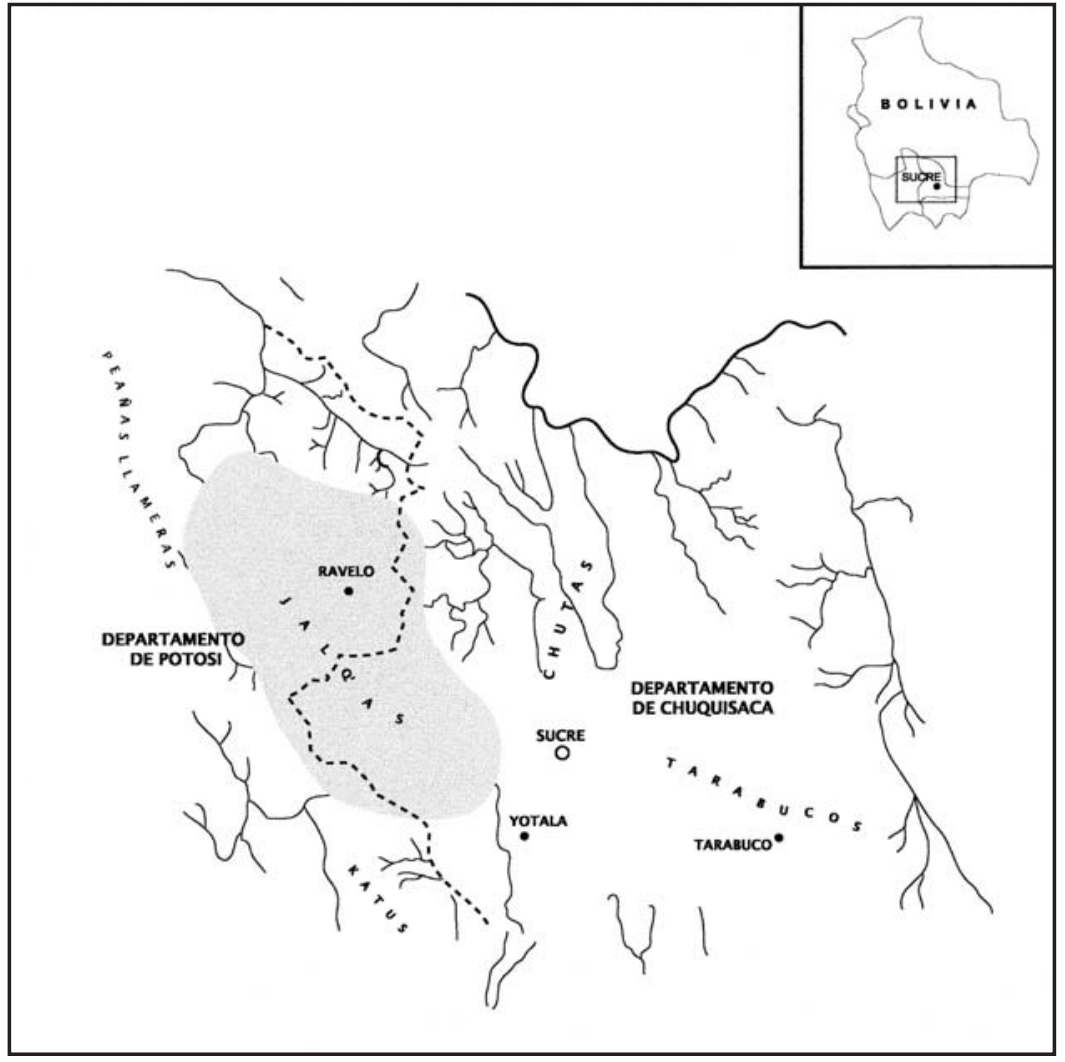

Figura 1. Mapa de ubicación del territorio jalq'a en los Departamentos de Chuquisaca y Potosí, en Bolivia
Después de la Reforma Agraria, los jalq'a están organizados mayoritariamente en comunidades de ex hacienda, aunque quedan algunos pocos ayllus originarios: en Qharaqhara, en Ravelo (el antiguo Moromoro) y en Quilaquila. A diferencia de los grupos étnicos norpotosinos, los jalq'a no tienen una organización político-social segmentaria, centralizada y única para todo el grupo.

La unidad está dada por los mitos de origen, la música y los bailes, algunos aspectos del sistema religioso y, sobre todo, por el vestuario, que los distingue nítidamente de sus vecinos. La identidad está confirmada por el nombre "jalq'a" con que se autodenominan, diferenciándose de los grupos cercanos, a quienes designan como llameros (al occidente), tarabucos (al oriente), ch'utas (alrededores de Sucre) y katus (al sur).

El problema más importante que plantean los jalq'a es el de la formación de su identidad. Al parecer, ésta se ha constituido sobre los restos de los señoríos prehispánicos de los Qharaqhara y de los Moromoro, por el noroeste del área y de parte del señorío de los Yampara, por el sureste.
Pero no sabemos cuándo se plasmó esta identidad. Los jalq'a no aparecen como grupo étnico en los documentos de la Colonia ni de la República y todo hace suponer que se trata de un proceso relativamente reciente, tal vez algo posterior a las grandes rebeliones indígenas de fines del siglo XVIII, tomando forma a lo largo del siglo XIX. Si es así, ello nos habla no sólo de desestructuraciones en el mundo andino, sino también de reestructuraciones y creaciones muy modernas de identidad étnica, hoy día perceptibles en casi todo el ámbito boliviano.

Se entiende, pues, el interés que tiene para nosotros acercarnos a una mejor comprensión de cómo se ha dado este proceso creador de identidad entre los jalq'a, examinando aquellas estructuras de pensamiento que nos pueden revelar la música, los tejidos y el discurso religioso.

Por "discurso religioso" estoy entendiendo -de manera provisoria- todas aquellas manifestaciones que tienen que ver con deidades: los rituales y ceremonias, las fiestas de culto, el "discurso verbal sobre los dioses", en cierta medida el mito, 
las representaciones plásticas de los dioses y, sobre todo, los supuestos semióticos de construcción de significaciones relativas a estas deidades. Mi enfoque, aquí, es restringidamente semiótico y no abordaré aspectos sociales, políticos, económicos o históricos, que son muy importantes pero por el momento no pertinentes.

Mi propósito es dar unos primeros pasos para tratar de desentrañar las relaciones internas que hay entre el discurso religioso y la música en los jalq'a, a partir del calendario de fiestas estudiado por R. Martínez y de buena parte de sus notas de campo. Secundariamente, entre el discurso religioso y los tejidos de los jalq'a, estudiados por Verónica Cereceda.

Como se puede prever, la música está inextricablemente unida a la celebración de las fiestas del calendario. Rosalía Martínez lo explicará mejor que yo, desde el punto de vista musical específico: no soy etnomusicólogo. Pero lo que intento comprender son las relaciones semióticas íntimas que hay entre estos dos lenguajes, que aparecen tan entrelazados: cómo se interrelacionan, cómo se articulan y se distribuyen los papeles para la construcción de una significación -la del calendario- que, obviamente, no puede ser inconexa e incoherente. Ello, de manera inevitable, nos llevará a enfrentar problemas semióticos no resueltos del discurso religioso andino, cuyas soluciones esbozaremos sólo a título de hipótesis de trabajo.

Una de las primeras cosas que me llamó la atención cuando empecé a estudiar este problema, fue la aparente "pobreza" y la parquedad del discurso religioso jalq'a, en algunas de sus expresiones. Hablo en primer lugar del discurso verbal "sobre los dioses": en comparación con otras áreas donde he trabajado (Isluga, Chwani, etc.), aquí se ve poca expansión de las figuras individuales, poca riqueza de las configuraciones, casi nada de mito...

Esto me trae a la memoria una reflexión parecida que hice hace tiempo, al considerar el sistema religioso prehispánico de Cajatambo, en Perú. Si se comparan los mitos de Huarochirí, por ejemplo, con lo que emerge de los documentos de extirpación de las idolatrías de Cajatambo, se tendrá la misma impresión de "pobreza" y "parquedad" del sistema de deidades, y de falta de relación de éstas con los mitos posibles de la región. Mientras en los mitos tan cercanos de Huarochirí hay una imaginación desbordante, transformaciones sorprendentes de los dioses, una imaginería casi barroca, relaciones conceptuales complejas entre los distintos planos de la percepción, de Cajatambo surgiría un universo repleto de huacas y malquis, es cierto, pero muy escueto en informaciones sobre cada deidad, sobre las significaciones de cada una, las relaciones entre ellas. Y ello, no sólo a causa de la situación de intimidación a que estaban sometidos los "informantes", sino como peculiaridad del discurso religioso mismo. ${ }^{2}$

Entre los jalq'a, a semejante sobriedad de expansiones corresponde parecidamente un calendario lleno de celebraciones de figuras de santas y santos (ya no de huacas y malquis). Mi hipótesis es que no se trata, por cierto, de "pobreza", sino que el discurso religioso -con excepción del mito- se realiza a través de varias semióticas, de las que "no se habla". En efecto, las fiestas del calendario son realizaciones de significación a cargo de las figuras de los dioses, a cargo del ritual y las ceremonias, pero también de la música, de los bailes, de las canciones, de los disfraces (forma, colores, texturas: semiótica plástica), de los objetos, de las comidas y las bebidas (como lo ha sacado a la luz R. Martínez en un artículo reciente), y de los espacios. Múltiples semióticas, la mayoría no-lingüísticas, que concurren en la construcción de la significación de una fiesta y que no consisten en enunciados verbales, como sí lo es el mito. ${ }^{3}$

El ritual, las ceremonias y otras conductas corporales reglamentadas dejan, pues, amplio espacio para la participación de esos otros lenguajes en la construcción de la significación. Y mi propósito es, así, tratar de comprender cómo se interrelacionan por un lado el discurso religioso - no ya como realización tal o cual de una semiótica precisa (como podría ser el ritual, por ejemplo), sino como significación virtual del calendario de las fiestas de los jalq'a- y uno de esos lenguajes, la música.

2 De todos modos, esto explica sólo parcialmente la "parquedad" del discurso jalq'a; queda pendiente un análisis más detallado de este problema.

3 Lo cual, de paso, nos lleva a considerar el lugar especial del mito en relación con el discurso religioso. 


\section{El calendario de fiestas: Primera visión}

Como se puede ver, estoy dando por sentado que el calendario anual de fiestas de los jalq'a tiene un sentido. Mejor dicho, tiene significados, y realiza un todo de significación en sí mismo. Aún más, mi hipótesis es que el calendario es en sí una semiótica-objeto: un conjunto significante de fiestas, armado en base a la articulación de figuras de santos, santas y deidades andinas, que va construyendo una significación a lo largo del año. Ya veremos cuál.

No es fácil darse cuenta de ello: a primera vista, lo que aparece es una serie de festividades de santos y santas, incluido Todos Santos, todos ellos del santoral católico, sin un sentido evidente. La única festividad que tiene cierto "sabor autóctono" es la fiesta de Carnaval, de la cual ya se sabe que la deidad principal aquí celebrada es el Supay o Diablo. ¿Qué sentido puede tener una secuencia de celebraciones de santos, ya establecidos por el santoral, para la sucesión de los meses del año?

Pero hagamos una primera constatación. Si el lector se fija en los tres calendarios que aquí tenemos -recogidos y estudiados por R. Martínezadvertirá que hay un claro predominio de santas y vírgenes: Mercedes, Dolores, Exaltación, Guadalupe, Santa Bárbara, Candelaria, etc. Hay algunos santos masculinos mezclados con ellas, y otros distribuidos en otra época del año -San Juan, San Pedro y San Pablo, Santiago- después de fiestas "tan católicas" como Pascua, Espíritu, Santísimo.

Puede extrañar que no mencione a una figura tan conocida como es la Pachamama, generalmente entendida como diosa andina de la fertilidad. Pero ocurre que en esta región jalq'a, la Pachamama es celebrada, efectivamente, a lo largo de todo agosto, pero es una deidad de culto privado y casi clandestino: no hay una fiesta abierta dedicada a la Pachamama en la cual participe toda la comunidad. La Pachamama no pertenece al calendario de fiestas.

Una segunda constatación: en los tres calendarios hay un período, de más o menos unos diez días, entre agosto y septiembre, en que se celebra una serie de santas y santos, en sucesión apretada, con breves interrupciones. Es como si los jalq'a hubieran querido concentrar, arbitraria y voluntaria- mente, un máximo de santos a quienes rendir culto estos días.

Digo "arbitrariamente" porque muchos de estos santos y santas no son celebrados aquí en su fecha propia, marcada por el santoral. Y son vueltos a celebrar en su fecha correspondiente, en el transcurso del año. Así, por ejemplo, en la comunidad de Purunkila, Guadalupe se celebra el 14 de septiembre, pero su fecha propia es el 12 de diciembre, en la cual es nuevamente celebrada. Santa Bárbara es también celebrada entre el 14 y el 16 de septiembre, pero "su" fecha es el 4 de diciembre, en que nuevamente es festejada. Y el 6 de enero, con el nombre de Reyes, celebran una vez más a Santa Bárbara (Figura 2).

En la comunidad de Potolo se da lago parecido: celebran el 15 de agosto a Asunción (Asunta) que, por varios datos que tenemos, es identificada con Mercedes, cuya fecha, sin embargo, es el 24 de septiembre. Y el 2 de febrero, con el nombre de Candelaria, vuelven a celebrar Mercedes. El 15 de septiembre mucha gente de Potolo va a festejar La Virgen del Abra, que es Dolores, a una comunidad cercana. Y el 24 de septiembre van en peregrinación a la Virgen de Soroqoto, que es propiamente Mercedes (Figura 3). Exactamente la misma situación que se da en las comunidades de Marawa, Iru Pampa y Majada (Figura 4).

Se trata, como se ve, de un manejo de santos y fechas, cuyo sentido veremos luego. Por ello cla-

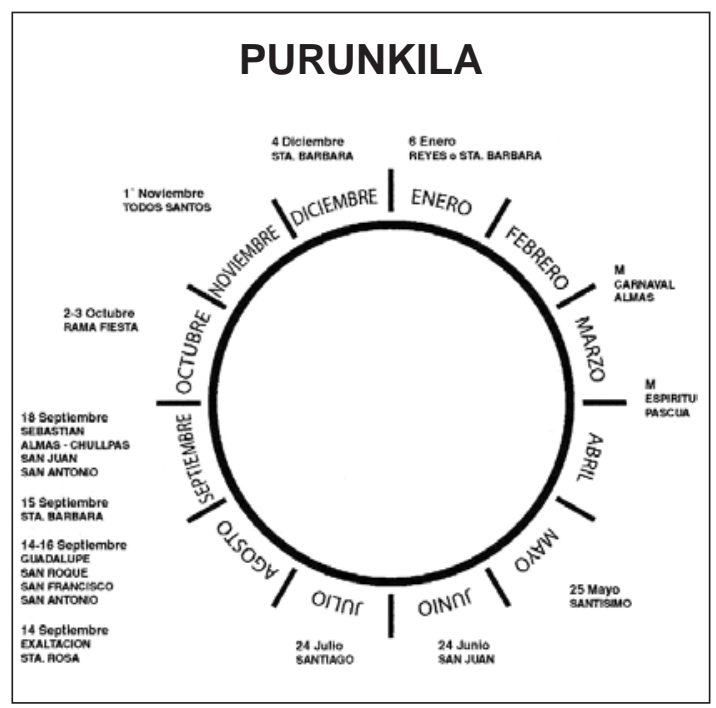

Figura 2. Calendario de fiestas de Purunkila. 


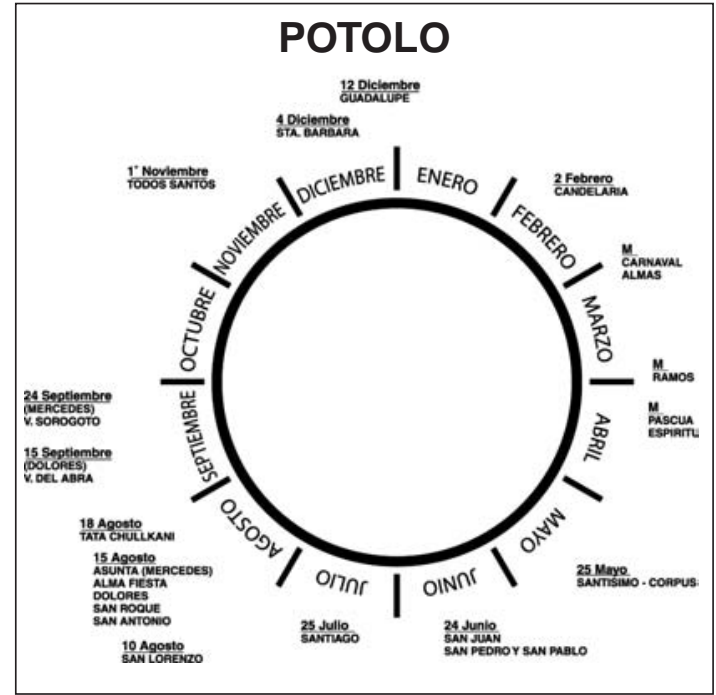

Figura 3. Calendario de fiestas de Potolo.

ramente muestra que el calendario de fiestas es algo "arreglado", algo "hecho", y no una sumisión a santos y fechas ya establecidos por el calendario oficial de la Iglesia.

Una nueva observación: adelantando algunos argumentos, que podremos constatar que después de Todos Santos el sentido de las fiestas "se mueve hacia Carnavales". Esta es una percepción dada por el dato musical. En efecto, ya con Santa Bárbara, se empieza a tocar la música de Carnavales, cuyo uso se va intensificando para culminar con el Carnaval mismo (fiesta de fecha móvil; generalmente cae entre mediados de febrero y comienzos de marzo).

Finalmente -y de nuevo en base al dato musicaldespués de Carnavales viene otro período del calendario, que empieza con Pascua entre marzo y abril, y termina con Santiago, en julio. Se trata de un período de fiestas menores, de poca intensidad, donde no hay ninguna celebración de santas o vírgenes.

Tenemos así un calendario de fiestas con tres períodos bien delimitados:

a) Aquellos 10 días intensos y abigarrados de fiestas de santos, y particularmente santas, de agosto/ septiembre.

b) Luego, con Todos Santos intermediados, ese nuevo período largo que va desde diciembre has-

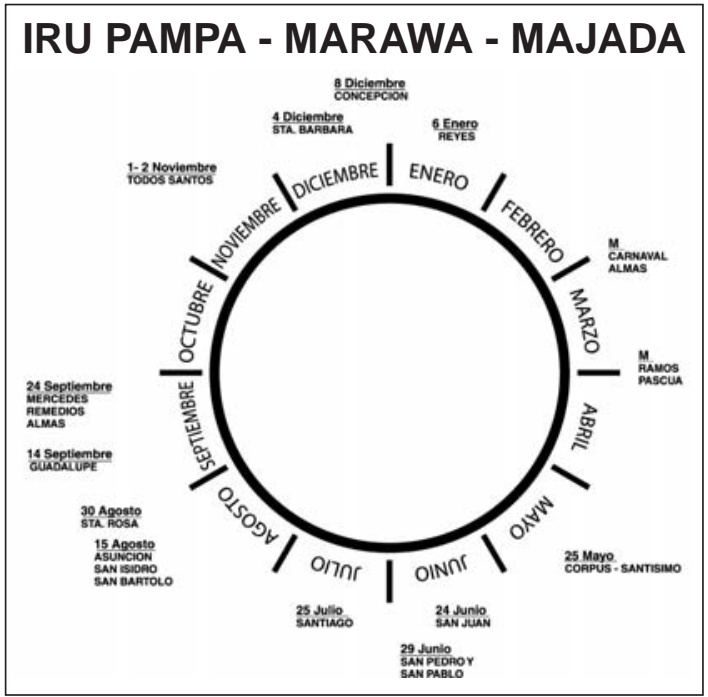

Figura 4. Calendario de fiestas de Iru Pampa - Marawa - Majada.

ta febrero/marzo, que empieza con celebraciones de santas y termina con Carnaval, las fiestas más fuete del año.

c) El período que sigue a Carnavales, de fiestas menores, de santos masculinos, que empieza con Pascua y termina con Santiago.

Sobre Todos Santos: conviene señalar que no es la única festividad dedicada a los muertos; éstos son también recordados un día de fiestas de agosto/septiembre y otro día de Carnavales. Ya examinaremos más de cerca este punto.

Pero antes de seguir analizando el calendario, nos vemos obligados a hacer un largo paréntesis para discutir algunos puntos relativos al Diablo, la Pachamama y la situación particular de los jalq'a.

\section{El Saxra, la Pachamama y los jalq'a}

En un trabajo anterior (G. Martínez 1983) dedicado a una de las figuras centrales del panteón andino -el dios de los cerros- pudimos advertir con claridad que una de las manifestaciones más frecuentes de esta deidad era de una forma tal que combinaba fuertes poderes creativos y genésicos con una gran capacidad de destrucción y desorden. En esta manifestación, ctónica, demoníaca, de las deidades del ukhu pacha, el dios del cerro otorgaba abundante ganado, buenas cosechas, riquezas metálicas (minerales y dinero) y era también el dador de música: era en sus "lugares", entre 
las rocas o con agua, donde se ch'allaban los instrumentos musicales. Y era identificado con los nombres de Diablo, Demonio, Wak'a, Saxra o Supay. La figura más conocida de esta deidad es el Supay o Tío de las minas. Pero esta figura alternaba con otra manifestación de dios del cerro, en la cual predominaban los valores de conservación de la vida, y de orden y tranquilidad social. Lo importante de todo esto es que muchas veces un mismo dios del cerro manifestaba a la vez, o sucesivamente, estos valores, haciendo de tales deidades figuras extremadamente ambiguas y elusivas.

Ahorrándonos aquí argumentos y detalles de análisis: pudimos llegar a la conclusión de que la estructura lógico-semántica de base, que regía estas manifestaciones, combinaba dos categorías heterogéneas como Creación vs. Conservación y Orden $v s$. Desorden, en una sola estructura como esta (Figura 5):

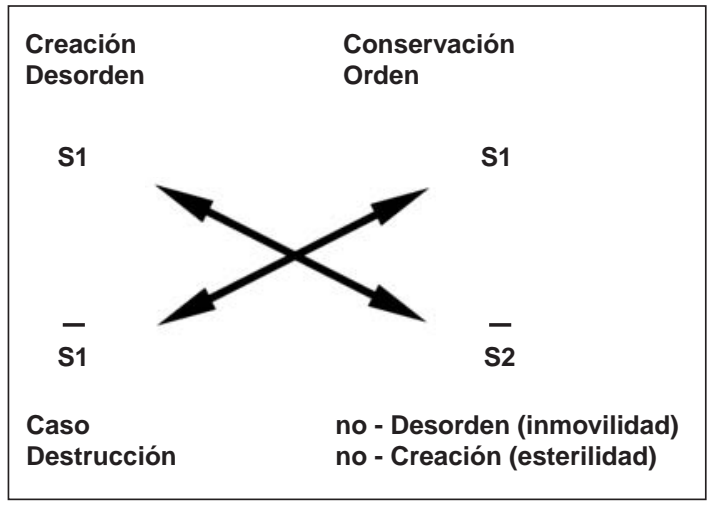

Figura 5. Estructura lógico-semántica de base.

Una estructura de esta índole (que en realidad es un epistema de la cultura andina) nos ayudaba a comprender no sólo los dioses de los cerros, sino también deidades andinas del pasado. Entendiéndose, además, que una misma deidad puede ocupar sucesiva o simultáneamente cada una de estas posiciones lógico-semánticas. Es, pues, la tematización y, luego, la representación en figuras definidas por la tradición cultural andina, lo que produce las diferentes manifestaciones concretas de las deidades. Por lo tanto, tal explicación no puede llevarnos a seguir pensando en manifestaciones separadas, diferenciadas y sin relación una con otra: la perturbadora ambigüedad, el deslizamiento de una figura en otra, negación de papeles y rasgos que en un momento dado son afirmados en el discurso, son "parte de la manifestación" de estas deidades no sometidas a la lógica de los contrarios: como se sabe la característica de estos discursos (llamados "míticos") es la afirmación simultánea de los contrarios y, yo diría, hasta de lo contradictorio.

En oportunidad de aquel trabajo yo no afirmé con vigor la identidad entre el Supay y el dios del cerro. Ahora lo hago: para mí, el Supay de las minas y el dios del cerro Wak'a son una y la misma cosa. Las únicas figuras que no son identificables con las anteriores son aquellas que adoptan las posiciones no-S1, o no-S1 + S2. Una afirmación así, por supuesto no es una cuestión de decisión personal: va en ello una comprensión adecuada de lo que son las deidades andinas en tanto creaciones de significación.

En aquella oportunidad también, me llamó poderosamente la atención que la figura de dios del cerro Wak'a, demoníaco, creador de metales, dador de dinero, de ganado y de música, diera una imagen tan cercana y sorprendente de lo que es la fecundidad femenina. Tanto es así, que yo hablé entonces de la "configuración uterina": metales gestándose en las entrañas de la tierra, cavidades uterinas y agujeros creacionales de donde emerge el ganado, aguas subterráneas como líquido amniótico, donde pululan pequeños ánades... Ciertamente, es toda una imagen de la gestación femenina, pero atribuida a una divinidad que, hasta el momento, aparecía como definitoria de la potencia sexual masculina.

Tampoco entonces afirmé con vigor la identidad del dios del cerro con la Pachamama, es decir, del Diablo o Saxra con la Pachamama. Ahora también lo hago: lo que se ha dado en llamar la "Pachamama" no es, semióticamente, otra cosa que la tematización y la figuración femenina del Diablo-Dios del Cerro. O, si se quiere, se trata de una misma entidad masculino/femenina, bisexual o andrógina; qhari-warmi, como dicen en el área quechua. La Pachamama actual, entendida como una deidad exclusivamente femenina, sin relación con ninguna divinidad masculina, diosa de la fertilidad agrícola andina, al modo de una Démeter mediterránea, madre generosa, bondadosa y protectora es un cliché, creación de diversas fuentes, y extremadamente ideologizada. 
Son varios los argumentos que apoyan esta afirmación y no podré repetirlos todos. Desde luego, la Pachamama es no sólo una deidad agrícola, sino también ganadera: como el dios de los cerros provee también de abundante ganado. Tiene que ver directamente con la minería: es bien sabido que ella "habita" en el interior de las minas y es invocada por los mineros ante el peligro; se sabe bien que ella recibe culto en las minas junto con el Tío para las mismas fiestas. En el área rural del norte de Potosí, para las fiestas de julio y agosto, que son meses "del Diablo", se le rinde culto a la pareja Pachamama-Pachatata (Platt 1983: 54 y siguientes). Para Carnavales, el Saxra se aparece como hombre para engañar a las mujeres, y como mujer para engañar a los hombres. Firestone (1988: 37) cita a Rigoberto Paredes diciendo que entre los aymaras del lago a la Pachamama la llamaban Pacha Achachi. Pero achachi es también "abuelo", el término de parentesco con que designan al dios del cerro (achachila). Y BouysseCassagne y Harris (1987: 48) confirman el uso de achachila aplicado a la Pachamama. Se dice que mientras el Saxra da la música, la Pachamama da los tejidos. Pero en Chumbivilcas, Perú, la Pachamama da los wayños del Carnaval a los yatiris (Roel Pineda 1966: 38). Y en la región jalq'a los tejidos también son dados por el Diablo... Establecer una diferencia tajante entre Pachamama y el Diablo es, pues, cuando menos, una imposición de nuestro pensamiento, tributario de la cultura europea. Pienso que una cita -que me fue proporcionada por Verónica Cereceda- de Chipaya, es bastante concluyente. El interlocutor, hablando de Pachamama, dice:

"Pachamama es otra que la Virgen María. Pachamama se le puede decir a los volcanes, al Tata Sabaya, eso. Es uywir mallku, uywir t'alla. (...) Como humano viene en el sueño. Medio verde, chalequina verde, falda azul celeste, con sombrero oro (de paja). Viene pidiendo: 'Hágame el favor de invitarme. No tengo qué comer'. Después se le hace una paguita. Jovencita. 'yo quiero mantener a todos los que aman'. Pero igual viene hombre, joven, verde y azul. Sabe conversar bien cariñosamente" (Cereceda 1982 Ms).

En estas palabras no sólo se identifica a la Pachamama con los cerros y los dioses de los cerros, sino se afirma también en la ambigüedad sexual de esta deidad.
Todo esto, pues, nos permite deducir, en la estructura de base arriba expuesta, la categoría masculino vs. femenino, sobrepuesta a las otras dos, en una condición jerárquicamente superior. De esta manera, habrá figuraciones, ya sea masculinas, ya sea femeninas, o incluso masculino-femeninas tal vez, en cada una de las cuatro posiciones del cuadrado semiótico, en las diferentes manifestaciones del discurso andino sobre los dioses.

Nos queda un último tema por tratar sobre la Pachamama, antes de volver a nuestro calendario jalq'a de fiestas. Es el tema ya bien conocido de la identificación entre la Pachamama y la Virgen (María), operada por la Iglesia desde los primeros días de la Colonia. Todos sabemos que dicha identificación efectivamente se ha producido en la población andina, al punto de que hoy, en vastas regiones bolivianas, la Pachamama es llamada mayormente "el Virgín" o Wirgina.

Pero en la adopción de la Virgen como figura de la Pachamama, resulta inevitable escuchar los ecos de la identidad ya señalada entre la Pachamama y el dios de los cerros. Teresa Gisbert, que trata el problema desde el punto de vista iconográfico, señala con abundancia de datos el esfuerzo de los sacerdotes españoles por reemplazar los cultos autóctonos a los cerros por el culto a la Virgen María:

"Ramos, en su texto sobre Copacabana, siguiendo la teología agustina enunciada en la "Ciudad de Dios", crea la teoría que permite identificar a María con un monte. Este mito emigra de las orillas del lago Titicaca a Potosí, dejando a su paso una estela de vírgenes superpuestas a los Apus o montes que habian recibido culto en los tiempos prehispánicos, buen ejemplo de esto son los Pucarani y Sabaya, ambas fundaciones agustinas. De la identificación de María con un monte, sustentada teológicamente, a la identificación de María con la Pachamama sólo hay un paso y el proceso se dio tanto a nivel rural y popular como a nivel erudito-eclesiástico" (Gisbert 1980: 20).

En realidad, para los andinos no había necesidad de ninguna justificación teológica y no había necesidad de dar ningún paso para realizar tal identificación, puesto que en la conceptualización andina la Pachamama es también un cerro masculino. Y es esto posiblemente lo que mejor explica la facilidad de tal adopción por la gente andina. 
A lo que quiero llegar es a que la evidencia de tal identidad no queda relegada a los siglos de la colonia: continúa en nuestros días. Y, de hecho, es particularmente perceptible en la región jalq'a de Sucre, donde las vírgenes "de piedra" -léase huacas - a las que se rinde culto son innumerables, y muchas de ellas están ligadas a un cerro y tienen su capilla en el abra del cerro; son las conocidas Vírgenes del Abra. No las conozco a todas, pero las hay desde ya en la misma ciudad de Sucre, otra cerca de la comunidad de Potolo -la famosa Virgen del Abra-, otra en el cerro Chatakila, la Mamita Chatakila. Con seguridad hay más.

Una buena prueba de esto es la Virgen del Abra, recién mencionada, cerca de Potolo. Si se admite que es el Supay quien inspira la música y es la Pachamama quien inspira los tejidos, ocurre que al lado de la capilla de la Virgen del Abra hay una roca que otorga ambos dones: los hombres que quieren "pedirse" para la música deben romper la roca, sacando pedazos de ella, y llevándose el fragmento a su casa. Las mujeres hacen otro tanto para tejer bien.

La mejor demostración está, sin embargo, en el caso del Tata Ch'ullkuni, también de la comunidad de Potolo: es una cruz crecida en un thago (un árbol nativo, el algarrobo) que "apareció" hace tiempo en el cerro Ch'ullkuni. De ahí fue trasladada a otro cerro, donde han construido una pequeña capilla: la imagen que representa al Tata Ch'ullkuni ¡es una virgen pintada sobre una piedra! Pero tata, se sabe, es un apelativo masculino.

Podemos, pues, afirmar que estas vírgenes representan al dios del cerro en cada caso. Es posible argumentar que simplemente se trata de una tradición, ya encarnada en la gente, sin otro trasfondo, lo que no sería una buena explicación antropológica. Pero, dejando de lado otras consideraciones, el hecho es que, tradición o no, la figura Virgen-Cerro (que no es muy distinta a la de mallku-t'alla) sigue funcionando plenamente y con toda vitalidad.

Nos podemos preguntar por qué los jalq'a han elegido representar preferentemente al dios del cerro con una figura femenina, en lugar de hacerlo -como en otras regiones- con figuras masculinas, como puede serlo una cruz (los tatas) o la imagen de algún santo (Tata Bombori, Tata Quillacas). La hipótesis que estamos manejando con Verónica Cereceda es que ello forma parte de una ideología de los jalq'a, que pone justamente el acento en privilegiar los aspectos femeninos del Saxra y, en general, en el supuesto asumido por los jalq'a de un rol femenino en relación con sus vecinos, los llameros y los tarabuco (del mismo modo que es femenina la mitad de abajo en relaci6n con la mitad de arriba, en el mundo andino).

Ello estaría confirmado por los análisis de los tejidos que hace V. Cereceda; ella lo dirá mejor que yo: los contenidos fundamentales de estos tejidos son, justamente, lo creacional, lo caótico, el mundo oscuro de las entrañas de la tierra, la creación incesante e indiferenciada de animales no domésticos e indomesticables: sapos, cóndores, vizcachas o animales irreales, que son precisamente "del Saxra", pero también "de la Pachamama". De alguna manera que todavía no alcanzamos a entender bien, los jalq'a han elegido esta posición estructural de lo creacional y del desorden (posición femenina) para definir su identidad de grupo, frente a sus vecinos. De alguna manera, que seguramente R. Martínez confirmará, esto se expresa también en la música: en la región jalq'a, para Carnavales, a partir de un momento los instrumentos propios de este período son tocados en forma conjunta, produciendo una inevitable sensación de caos.

Un último aspecto a señalar en este tema de la relación Virgen-Pachamama. Es bien sabido que los andinos identifican a la Pachamama no sólo con la Virgen María, sino con muchas de sus figuras particulares. Los andinos no se sienten obligados a ser expertos en teología y desconocen que para la Iglesia la Madre de Cristo, la Virgen María, es una sola, con distintas advocaciones.

El tema no se ha estudiado bien y desconozco si la adopción de una u otra virgen obedece a alguna lógica especial. Pero está claro que en algunas partes la Pachamama es Asunta (norte de Chile, norte de Potosí: tía pachamama asunta lawisa; Platt 1983); en Oruro y otros lugares del norte de Potosí es Concepción, la Virgen del Socavón, pero en otras regiones Candelaria "es Concepción" o es "su hermanita gemela".

Naturalmente, en esta profusión de vírgenes entran también las santas... y los santos. Después de todo lo dicho, no debe extrañarnos que haya la Virgen de San José y la Virgen Corazón de Jesús. Así como en algunos lugares hay el Tata San 
Warawara (por Santa Bárbara: Bouysse-Cassagne y Harris 1987: 51) y como alguna vez Rosalía Martínez ha oído nombrar como Virgen a Santiago. Recordemos el dato reciente del Tata Ch'ullkuni, representado por una virgen.

Finalmente, aquí en Sucre -y en la región jalq'alas vírgenes, santas y santos son declaradamente algunos (la mayoría de las santas) "de la parte de Pachamama", es decir, del ukhu pacha: generalmente, los que "son piedra"; otros "de la parte de Gloria", es decir, del Cielo o janaj pacha, de "la parte de Dios". ${ }^{4}$ Entre los jalq'a de las comunidades de las que aquí hablamos, las vírgenes/santas Guadalupe, Candelaria, Dolores, Mercedes, Remedios, Rosario, Santa Bárbara y Concepción "son Pachamama".

Lo que quiere decir, pues, que la virgen o las múltiples vírgenes y santas que hemos visto no pueden ser entendidas como la deidad católica que aparentan ser: detrás de ellas están la Pachamama y el Saxra.

Ya podemos volver a nuestro calendario jalq'a de fiestas.

\section{De vuelta al calendario: Las fiestas de agosto/ septiembre}

Después de lo dicho, se puede comprender que en ese período de más o menos 10 días de agosto/ septiembre, que se celebra en cada comunidad, lo que se está festejando en las vírgenes y santas son las distintas figuras de la Pachamama. En Potolo se celebra en esos días a Dolores, Asunta y Mercedes. Pero, como hemos señalado, mucha gente va también a rendir culto a una comunidad cercana a la Virgen del Abra ya mencionada, el 15 de septiembre, que es la Virgen de los Dolores; y aun van a celebrar a otra comunidad algo más lejana: la Virgen de Soroqoto, el 24 de septiembre, que es Mercedes. Todas son figuraciones de la Pachamama, y varias de ellas "son piedra".

Algo parecido ocurre en Marawa-lru Pampa: aquí se celebra Asunción, Santa Rosa, Remedios y

4 Otros hablan de tres divisiones cosmológicas: el janaj gloria, el $u k h u$ gloria y el kinray gloria: éste último corresponde a una zona intermedia que está más cerca del $u k h u$ gloria. La mayoría de las vírgenes citadas que son "del lado de Pachamama" son de kinray gloria.
Mercedes, mientras en Purunkila celebran Exaltación, Guadalupe y Santa Bárbara para este mismo período. No sabemos aún si cada una de estas advocaciones representa una tematización más particularizada del gran tema general de la fecundidad/creación, o si cada una tiene rasgos particulares que permitan distinguirlas entre sí.

Ahora debe observarse también que en cada comunidad, en este mismo período, tiene lugar también la celebración de santos masculinos. En Potolo se festeja a San Lorenzo, San Roque y al Tata Antonio. Pero también al Tata Ch'ullkuni, que ya hemos mencionado: aquella cruz que apareció en un cerro cercano, crecida en un thaqo. De manera muy interesante, Tata Ch'ullkuni se celebra al final del período y su fiesta debe ser un martes o un viernes, días que, como se sabe, son propios del Saxra. Además, de alguna manera se lo identifica con la Virgen Mercedes:

"Pasada Mercedes, Tata Ch'ullkuni no tiene fecha fija, pero tiene que ser martes o viernes, mismo que Mercedes. Mercedes no es aparte (R. Martínez s/f Ms).

No hay necesidad de mucha imaginación para sospechar que el Tata Ch'ullkuni es una representación del Saxra, de un dios del cerro. Además de todo lo dicho, su lantin -su figura "de reemplazo"- está también en otro cerro, situación que se repite en la comunidad de Purunkila con mayor claridad aún: una de las deidades más importantes de Purunkila es San Sebastián, que es el cerro Telapaques. En esta comunidad hablan indiferentemente de Sebastián o Telapaques. Es también una cruz, aparecida en un cerro, pero esta vez de molle (otro árbol que el thaqo) y es la cruz de pukara más importante de todas para el Carnaval. Obviamente, Sebastián-Telapaques es el dios del cerro, el Supay. Aunque, por supuesto, ningún Purunkila lo declararía así. ${ }^{5}$

En Purunkila otros santos masculinos son celebrados junto a las vírgenes ya señaladas y junto a Telapaques, para este período de agosto/septiem-

\footnotetext{
5 El problema es algo más complejo, sin embargo, que lo dicho aquí: no es posible afirmar que estas cruces son "solamente" un dios del cerro. También hay contenidos de Gloria en ellas, como que se las hace bautizar. Algo cercanamente semejante ocurre con Santiago. Una investigación posterior deberá precisar el alcance de estas ambigüedades.
} 
bre: San Roque y San Francisco (ique son "el mismo"!), San Juan y San Antonio.

En Iru Pampa-Marawa no hay un dios del cerro tan evidente como en Potolo (Ch'ullkuni) y en Purunkila (Telapaques): se celebran San Isidro y San Bartolomé, pero de ambos sospecho fuertemente que son representaciones del Supay, particularmente de San Bartolomé, "santo cabrero" (de las cabras), que está muy cerca de las figuraciones del Diablo: barba, pezuñas y cuernos de macho cabrío, en la imaginería católica impuesta.

Si es efectivo que todos los santos masculinos son representaciones del Supay, como creo, y si todas las vírgenes son representaciones de la Pachama$m a$, como creo con mayor fuerza aún, resulta, entonces, que lo que se está celebrando en este período de agosto/septiembre es la pareja Supay/ Pachamama, tal como ocurre en otras partes andino-bolivianas durante el mes de agosto. Sólo que en las otras regiones (Potosí, Oruro) la pareja es celebrada abiertamente como Supay/Pachamama, con las imágenes y nombres propios de estas deidades: Tío/Pachamama, o Pachatata/Pachamama (Platt 1983).

Por lo demás, ya hemos dicho que en la región jalq'a, agosto es también el "mes de la Pachama$m a$ ", aunque bajo esta figura se la celebra individual y calladamente por las noches. En las fiestas abiertas del calendario festivo aparece como Mamita Asunta, Mercedes, Dolores u otra.

Si todo esto es así, ocurre entonces que en estas fiestas se está instalando y afirmando la posición semántica de Creación, que ya vimos en la estructura profunda mostrada al comienzo. Creación, es decir fecundidad, abundancia, fertilidad. No sé si inherentemente también la posición de Desorden, que con frecuencia la acompaña, pero creo que no: como espero que veamos más adelante, el calendario parece bloquear o suspender parcialmente las ambigüedades de la estructura.

\section{Las almas}

Dentro del período que examinamos (agosto/septiembre) ya hemos dicho que se deja un día para las "almas", principalmente para recordar los muertos del año anterior, celebración que ocurre en todas las casas donde han habido muertos re- cientes. Aquí se repite la ceremonia que se hace en la fiesta de Almas/Todos Santos (1 y 2 de noviembre de todos los años): los deudos preparan y sirven comida especial, y arman un altar esperando al alma, que llega a las 12 del día. Hay rezos, llanto y tristeza; en estas casas no se puede tocar música.

"Alma Fiesta" se hace también en Carnavales, igualmente reservando un día para esta recordación. Hay, pues, tres oportunidades en el curso del año en que se recuerda a las almas: para agosto/septiembre, para Todos Santos y para Carnavales. Pero esta fiesta también es llamada "Alma Mundo" y dedicada a las almas de todo el mundo, conocidas y no conocidas.

El estatuto semántico de las almas, y por tanto de esta fiesta, es bastante elusivo en esta región. Para la mayoría de la gente las almas "son Gloria". Es decir, serían de janaj pacha, del cielo, de "la parte de Dios". Pero "vienen del lado de Potosí, del lado de su Dios", como si este Dios fuera otro y no fuera compartido plenamente por la gente viva. Además, en Purunkila, a Alma Fiesta también "Chullpa Fiesta", es decir, una fiesta dedicada no sólo a los muertos recientes, sino también a los chullpas o "gentiles", quienes, por definición, no son bautizados, puesto que eran las gentes de un pasado inmemorial, la humanidad presolar. Sería la primera vez que veo calificar a los chullpas como seres de Gloria y más bien veo en ello una expresión de influencia católica, no bien asimilada. Por lo demás, en todas partes la celebración incluye desenterrar calaveras del cementerio y guardarlas en casa, velándolas. Reminiscencias aún fuertes del viejo culto andino prehispánico a los muertos y a los antepasados.

Concuerdo con Olivia Harris (1983), para quien los muertos son del ukhu pacha, del mismo ámbito de Pachamama y del Diablo. Y comparten con estos dos últimos su poder genésico, fecundador y creador, deidades de la fertilidad y de la abundancia.

Si esto es así, resultaría, pues, que la inclusión de una celebración de las almas de este período de agosto/septiembre no sólo no contradice el contenido de Creación que postulamos para estas fiestas, sino que lo refuerza. Con mayor razón si se trata declaradamente de una fiesta dedicada a los 
chullpas, que en el mundo andino connotan siempre fertilidad. La misma interpretación sería válida para la Fiesta de Almas de Carnavales y, por supuesto, también para Todos Santos.

\section{Hacia el Carnaval}

Inmediatamente después de Todos Santos empieza a prepararse el Carnaval. Esta afirmación está basada en el hecho de que apenas terminado Todos Santos ya puede tocarse abiertamente música de Carnaval. Incluso, en el atardecer del día 2 de noviembre, cuando los deudos se despojan de sus ropas de luto y éstas son arrojadas o enterradas, los acompañantes que hicieron la ceremonia de despojo de las ropas vuelven ya tocando música de Carnaval en sus charangos. También después de Todos Santos se puede empezar a tocar el erqe, que junto con el thurumi son los instrumentos más definitorios del Carnaval y del Supay. Pero según algunos datos el erqe se puede tocar desde antes, sólo que "no en el pueblo":

"El Carnaval se toca desde Todos Santos. En los cerros, las ovejeras tocan desde octubre, pero pasando el río, si entran al pueblo, se callan: aquí se toca desde Navidad no más. Se toca en los cerros o en lugares silenciosos, para que no oiga la gente. En cuanto llueve van a los cerros y ahí tocan erqe; si no llueve no van. Otros van a las rocas” (R. Martínez s/f Ms).

La oposición naturaleza/cultura está aquí funcionando claramente. Y la adscripción del erqe a "lo salvaje" resulta coherente con el carácter demoníaco del Carnaval y su deidad, el Supay.

Es a raíz de la celebración de una serie de fiestas de santas que preceden al Carnaval mismo, donde el uso de esta música se va intensificando, según los datos de R. Martínez. En este período, que va de diciembre a comienzos de febrero, se festejan algunas de las santas que ya fueron celebradas en agosto/septiembre. En Marawa-Iru Pampa-Majada, por ejemplo, se celebran en este tiempo Santa Bárbara (4 de diciembre) y Concepción ( 8 de diciembre). En Purunkila festejan a Santa Bárbara en su fecha y nuevamente a esta misma santa para Reyes (el 6 de enero), como se dijo. Y en Potolo, festejan a Santa Bárbara, Guadalupe y Candelaria (el 2 de febrero), virgen, esta última, que a veces es también llamada "Mercedes".
¿Será necesario recordar que en nuestra opinión son vírgenes que representan a Pachamama?

Pero hay algo interesante en estas fiestas de santas: con Santa Bárbara aparece el baile de warrimachus/q'ewas: hombres vestidos de mujeres, los primeros de axsu (pieza de traje femenino indígena), los segundos de pollera (traje femenino mestizo). Y se pelean a hondazos, al parecer realizando un tinku. No conocemos bien, ni entendemos bien todavía, el sentido de este baile. Tentativamente si el Carnaval, que viene enseguida después de estas fiestas es la afirmación del poder genésico masculino, el baile de warrimachus/q'ewas \{hombres disfrazados de mujeres) sugiere de alguna manera la construcción y afirmación del significado femenino del Saxra. Cual si en estas fiestas se afirmara el aspecto femenino del Saxra, y en Carnaval el aspecto masculino, conjugándose ambos en esta última festividad: Carnaval es "hombre y mujer" (aunque con mayor acento masculino). Podemos especular, pensando que el hecho de que se trate de "hombres disfrazados de mujeres" sería una evidencia del carácter sexual ambiguo de Saxral Pachamama, pero no estoy seguro de ello. También se podría sugerir que es una manifestación de desorden ("mundo al revés"), pero tampoco estoy seguro.

De cualquier modo, si la música define un período, como realmente ocurre, éste que va desde diciembre hasta el Carnaval debemos considerarlo como "preparación del Carnaval", y dentro del mismo espíritu de éste. Es en realidad "parte" del Carnaval. Y las fiestas que se celebran en él -fiestas de santas- entregan, pues, el mismo significado de Creación, fertilidad y abundancia. Un detalle resulta coherente con este contenido: el proyectil que se usa para hondearse en el baile de warrimachus/q'ewas, es de trozos de qhewayllo, un cactus (la "penca" a la que se han sacado las espinas) "que es comida de los chullpas", y ya se ha puesto de relieve el sentido de "fertilidad" que connota lo chullpa.

\section{El Carnaval}

A estas alturas de nuestro desarrollo está ya bien claro que el Carnaval (pujllay en quechua, en esta región) representa la realización plena de la posición semántica de Creación, de la estructura fundamental, dada por la figura central del Supay, la 
deidad en torno a la cual gira toda esta fiesta, la más importante y "fuerte" de todo el calendario. Tal sentido está claramente manifiesto en las pukaras: cruces que han crecido naturalmente en el árbol molle, que son bendecidas y se colocan en los cerros o, bien, simplemente cruces de madera. Para Carnaval, estas cruces son bajadas de las lomas, adornadas con los primeros frutos de las siembras que ya han aparecido: choclos (maíces) tempranos, lacayotes, angolas, muchas flores y pillos (guirnaldas) de rosquetas de pan. Las pukaras son llevadas a las chacras y buena parte de la celebración del Carnaval se hace bailando en torno a ellas. Cabe señalar que los músicosbailarines que tocan y danzan el pujllay son llamados mallkus: una de las escasísimas voces aymara que quedan en esta zona, con la cual -en las regiones propiamente aymara del altiplano y cordillera occidental- se designa a los dioses de los cerros y a los jefes étnicos. Del mallku del pujllay, es decir, del músico-bailarín, se dice que representa al Supay, y su pareja femenina, la warmi pujllay, a la mujer del Diablo; el traje del mallku está bellamente adornado de lentejuelas, multitud de espejos y bordados de vivos colores. Tocan el erqe y el thurumi ya mencionados, además del charango, en tanto la mujer toca solamente el erqe.

Pero, si bien en las fiestas anteriores no había aparecido con claridad, aquí la conjunción de Creación con Desorden aparece como el significado nuclear del Carnaval: el poder genésico, creacional de lo demoníaco, va de la mano con el Desorden y ambos apuntan inmediatamente al Caos y a la Destrucción. El Diablo es en extremo peligroso: crea, pero también destruye. Engaña y seduce sexualmente a sus víctimas y luego las mata y se las come. Da riquezas, pero se apodera de sus destinatarios. En el Carnaval se bordea realmente la Destrucción: en el último día de Carnaval, el Domingo de Tentación, cunden las peleas y los golpes, se derrama sangre. Todo esto hace que ésta sea una fiesta emocionalmente intensa, dentro de la cual hay "conflicto" y "proceso". De todo esto hablaremos pronto, al examinar los programas narrativos del calendario y del Carnaval mismo.

Por de pronto, está claro que está fiesta realiza el contenido de Creación/Desorden, lindando con la posición de Destrucción/Caos.

\section{Pascua y la otra mitad del año}

Una semana después de Carnaval, con Domingo de Ramos, comienza Pascua (fiesta también movible). Si Carnaval ha representado un clímax emocional -para todo el calendario- Pascua es su anticlímax: ella representa, en el discurso de la propia gente, la paz, el descanso, la tranquilidad y la restitución al propio ser. Una persona de la comunidad de Potolo, refiriéndose a la personificación de Pascua, dice:

"Pascua es parejita, tranquilo (...) viene con bueyecitos, ovejitas... tranquilamente viene ch'allando (asperjando con chicha (alcohol de maíz) para ver lo que se produce... Por mi parte, es importante que esté llegando Pascua, porque es tranquilo y trae su ganado” (R. Martínez s/f Ms).

Creemos no equivocarnos al atribuir a Pascua un significado de Orden y Conservación: conservación de la vida, orden, tranquilidad y paz social.

Pascua inaugura así un nuevo período de fiestas, pero de fiestas menores, de poca intensidad, como ya se dijo. Incluso la fiesta misma de Pascua no es tal fiesta: en Potolo es escasamente la realización de un pequeño qhatu (un mercado o feria), a donde llegan los que han ido a comprar animales a la feria de la Tablada, de Sucre, y donde beben un poco. Son, además, fiestas familiares y no fiestas colectivas, con participación de toda la comunidad: se invitan unos a otros, se celebran en las casas. Fuera de Espíritu y Santísimo, cuyo género es indefinido, se festejan sólo santos masculinos: San Juan, San Pedro y San Pablo (los tres dedicados al ganado doméstico) y Santiago, el 25 de julio, con el cual termina el período y vuelve a comenzar el ciclo anual. Santiago (protector del ganado caballar) merece una atención especial, pero no nos detendremos en él.

Como podemos ver, el calendario en su conjunto, a través de las fiestas y particularmente a través de las deidades a las que se rinde culto (figuras diversas de Saxra/Pachamama), va desplegando la significación por casi todas las posiciones semánticas de la estructura fundamental. Desde una posición de No-Creación y No-Desorden, al terminar el año, después de Santiago, pasa a una posición de Creación (donde no es evidente la realización del contenido de Desorden), en las fiestas de agosto/septiembre. Incorpora a este conte- 
nido la celebración de las almas y se dirige en proceso a construir la realización del contenido Creación y Desorden, en Carnavales, fiesta que está referida a la posición de Destrucción y Caos, hacia la cual peligra pasar. Finalmente, desde Creación y Desorden, pasa con Pascua a la posición de Conservación y Orden, para volver al punto de partida (Figura 6).

Dentro de este panorama "de sistema", la música cumple un papel decisivo: es ella la que define no sólo los períodos del calendario, sino que define el carácter mismo de cada período, su contenido. De no haber sabido que Carnaval "empieza inmediatamente después de Todos Santos", para nosotros esta festividad hubiera empezado simplemente en la fecha fijada por el calendario religioso. De no haber sabido que en Santa Bárbara, Concepción, Guadalupe y Candelaria se tocaba música de Carnaval, particularmente el erqe y el thurumi, no nos hubiéramos percatado que esas fiestas son "parte del Carnaval" y no hubiéramos advertido el significado de lo femenino del Saxra que parece afirmarse en ellas (baile warrimachus/q'ewas). Algo semejante ocurre con las fiestas de agosto/ septiembre: la participación de los bailes liweria y monos, a los que no me he referido, confirma también la referencia al Supay en esas fiestas.

Naturalmente, esto es sólo un problema del antropólogo y, desde luego, no de los jalq'a. Por

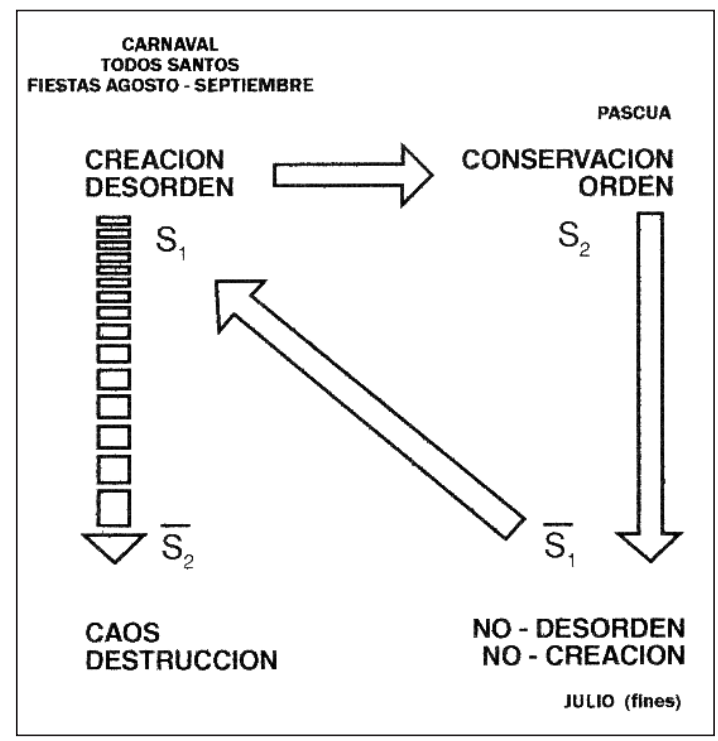

Figura 6. Significación desplegada por las posiciones semánticas de la estructura fundamental. supuesto, ellos manejan totalmente este juego de significaciones ocultas debajo de los disfraces y las apariencias, a las cuales uno accede a vislumbrar sólo de manera burda. Pero resulta enormemente interesante percibir cómo el discurso religioso y la música "se pasan" el papel de las realizaciones de una significación. Comprender de qué manera, específicamente la música, puede definir el carácter o significado de un período del calendario a través de la adscripción de instrumentos, temples y otros recursos que desconozco, me resulta aún difícil. Y entreveo que hay ahí un problema de "traducción" de una semiótica a otra, todo un sistema de connotaciones y equivalencias, que sospecho decisivo para entender estos procedimientos del pensamiento y de la cultura.

Sin embargo, la música desempeña un papel muchísimo más sutil y delicado en la realización de las significaciones que éste que acabamos de señalar. Para percibirlo necesitamos enfrentar el problema de los así llamados "programas narrativos" que desarrolla el discurso religioso en el calendario de fiestas. Y, a su vez, la comprensión de estos programas requiere del análisis previo de otros aspectos del discurso religioso. Permítaseme, pues, volver a hacer un largo paréntesis.

\section{Programas simulados y verdaderos}

El discurso religioso andino -como cualquier otro discurso religioso- es, en buena medida, ${ }^{6}$ y en un cierto nivel (el nivel narrativo de la significación), un discurso creador de Destinadores, los dioses: figuraciones del poder sobrenatural trascendente, con quienes el hombre podrá establecer una relación de Destinatarios, receptores del favor de los dioses.

Pero el discurso religioso andino -quizás más que otros- es un discurso fuertemente caracterizado por el juego entre las apariencias y las verdades (modalizaciones veridictorias: ser/parecer) y por estar siempre a medio filo entre el creer y el no creer (modalizaciones epistémicas). Ello hace de éste un discurso intelectual, que deja buen margen al humor. Me explicaré.

6 Estamos lejos de pensar que los dioses son "únicamente" eso. Son también, cuando menos, creaciones poéticointerpretativas del mundo. 
Como es fácil advertir, el discurso religioso -ya no solamente verbal-, tal como se da en el calendario de fiestas, por ejemplo, ocurre como la realización de acciones, como la ejecución de programas; programas desarrollados por los hombres con respecto a los dioses, y supuestamente programas de los dioses con respecto a los hombres, que llevan y producen significación.

Ya en el punto de partida hay una relación entre los hombres y los dioses regida, como decíamos anteriormente, por la relación entre verdad y apariencia: los dioses "parecen ser los Destinadores" que otorgan dones y favores, pero "no lo son" (puesto que son creados por los hombres); los hombres "parecen ser" los Destinatarios de los favores de los dioses, pero "son", en verdad, los Destinadores de los dioses: los hacen ser, les ordenan, los manipulan. Sin embargo, en los rituales, ceremonias y fiestas, los hombres actúan con los dioses "como si estos fueran realmente los Destinadores de los hombres. De aquí surge toda una serie de programas de los hombres hacia los dioses, pero son programas simulados".

Corrientemente, son programas orientados a "manipular" a los dioses: seducir a estos para que realicen algo en beneficio de los hombres; estos programas envuelven casi siempre la apariencia y la estructura de un intercambio de dones: los hombres "ofrendan" a los dioses algún objeto de valor (generalmente una "mesa", libaciones, comida), además de sus muestras de adhesión y sumisión, para obtener de los dioses buenas cosechas, salud, protección en un viaje, éxito en un negocio o cualquier otro bien.

En un primer acercamiento, todo hace pensar que el programa general desarrollado por los jalq'a en su calendario de fiestas es un programa de este tipo: un programa de manipulación de los dioses (de hacerlos hacer) para que éstos den, a cambio, un año agrícola exitoso: cosechas abundantes. A primera vista, el calendario de fiestas sería tal, que estaría estrechamente referido al ciclo agrícola, y consistiría en ir acompañando cada labor -la preparación del terreno y siembra, el cuidado y desbroce a chacras, la cosecha- con fiestas que realizarían este programa de "manipulación", donde se estaría encargando a las deidades (aunque el verdadero trabajo lo hacen siempre los hombres) la tarea de aportar con buenas cosechas.
Pero he llegado a la conclusión de que no es así. La referencia al decurso de las estaciones y año agrícola existe, sin duda. Pero me parece claro que la intención "fundamental" de la gente en el calendario de fiestas es otra. Hay un hecho decisivo: después del período de Pascua (la realización de la posición de Conservación y Orden) todas 1 as fiestas, hemos dicho, son menores, y no hay absolutamente ninguna fiesta, ni grande ni pequeña, que celebre la cosecha, los resultados del año agrícola, y que sea una fiesta de reconocimiento y de agradecimiento de la tarea cumplida por los dioses. De haber encargado a los dioses el programa de "producir un buen año agrícola", y ajustándose a los programas narrativos (condición inevitable), esta fiesta hubiera sido absolutamente necesaria, ya que ella hubiera representado el "reconocimiento del héroe": la sanción otorgada por el Destinador verdadero (los hombres), al Destinatario verdadero, ejecutor de la acción (los dioses). Ciertamente, a los jalq'a, en el calendario de fiestas, no les interesa el resultado agrícola (y no porque no sea importante).

Si no es el resultado agrícola lo que da "sentido" al calendario, ¿qué, entonces?

Saltándome argumentos, y a partir de una intuición, llego a la conclusión (como hipótesis provisoria) de que el verdadero sentido que se realiza a lo largo del calendario es un propósito de los hombres de "significar el tiempo": significar el año como la realización secuencial de las significaciones fundamentales que ya hemos visto (Creación/Desorden vs. Conservación/Orden). Del mismo modo que los andinos "significan" el espacio, construyéndolo como significación; también "significan" el tiempo.

Ahora bien, un programa de "significar el espacio" es relativamente fácil de cumplir: se construyen monumentos sagrados (iglesia, torre-campanario, plaza, altares, bóvedas y "hespitarios" dedicados a determinados santos, se nombran lugares) que definen centros, límites, recorridos, lugares de culto, orientación, se involucran cerros, etc. Las "objetivaciones" de esa significación del espacio son relativamente fáciles de construir y de instalar. Pero, ¿cómo se puede "significar el tiempo"? ¿Cuáles son las "objetivaciones" de una significación del tiempo? ¿En qué consistiría un programa de "significar" el tiempo? Sigo con la hipótesis: las objetivaciones que permitirían sig- 
nificar el tiempo no parecen ser otra cosa que "representaciones de la presencia de una deidad en un período determinado del año", que definen ese período según los significados que ya hemos visto.

Dos hechos abonan en esta interpretación: las grandes fiestas del calendario jalq'a (con excepción de las fiestas de agosto/septiembre, a las que nos referiremos luego) tienen todo el formato de "representaciones actuadas" -al modo de representaciones teatrales- y ellas el trato a la deidad (almas, Pachamama/Supay) sigue siempre el mismo esquema: las deidades son recibidas, festejadas y luego "despachadas".

Son representaciones que connotan a la deidad (tal vez el baile de q'ewas/warrimachus, para Santa Bárbara, Guadalupe y Candelaria) y/o la representan directamente. Todos Santos y las Alma Fiesta son claramente la representación de la venida de las almas, su banquete al lado de los vivos, su estadía por unas horas y luego su despedida (kacharpaya). En algunos lugares se representa vívidamente el episodio de un alma que no quiere irse, que quiere llevarse consigo un vivo, y a quien hay que arrojar con brusquedad: se le tiran piedras, se lanzan gritos.

Lo mismo pasa en Carnavales: el Supay llega el martes (en algunas comunidades antes), está ahí invisible bailando y tocando con los mallkus y las warmi pujllay, está de algún modo en la pukara, está en el ch'allaku a las chacras, herramientas, máquinas de coser, hace desastres el Domingo de Tentación, y luego es despedido (kacharpaya) el Domingo en la noche. Todavía en varias comunidades el Supay es representado en la despedida por una pareja de viejos, pobremente vestidos, a quienes se echa de la aldea. Y también en algunas partes (R. Martínez com. pers.) la Pascua -el período que sigue- es representada por una pareja hombre/mujer, bien vestidos, alegres, que entran con el "aire" de Pascua.

Pero, como se puede comprender, un programa de "significar el tiempo" mediante la representación de la presencia de los dioses no puede realizarse sino a través de programas "simulados". Son programas que, en su conjunto, constituyen un gran programa de base de "conjunción/disyunción" de los hombres con los dioses, en que los hombres hacen "como si" entraran en conjunción con la deidad representada y luego se disyuntaran de ésta. Sólo un programa así, creo, permitiría instalar sucesivamente las significaciones que harán del año "un tiempo significado" (¿tiempo trascendente?).

Pero, además, dicho programa adopta la apariencia y la estructura del esquema narrativo canónico: la ejecución de una acción (performance) por un sujeto activo que desarrolla una tarea difícil y que logra o no su objetivo, por decirlo simplemente. En este programa los hombres hacen "como si" se esforzaran para seducir a los dioses para que estos les otorguen las buenas cosechas, y hacen "como si" esta tarea fuera difícil y representara un esfuerzo y hasta un peligro. La simulación de este programa da así al calendario la apariencia de una acción que genera tensión y que desarrolla los tres momentos básicos del esquema narrativo: la adquisición de una competencia, la ejecución de la tarea difícil y la sanción. De ahí que se tenga la percepción de que en el calendario "hay un desarrollo" que, en estricto rigor, no existe. No al menos como resultado de una acción "verdadera".

Hemos señalado que las fiestas de agosto/septiembre parecen salirse del formato de la "representación actuada" que sí hay en las fiestas que siguen.

En efecto, aquí las celebraciones consisten básicamente en las ceremonias eclesiásticas: "vísperas de cirios", misa con cura en la iglesia, procesión, visitas con los bailes, comidas, bebidas, etc. Pero, como contrapartida, siendo éstas las festividades primeras, con las cuales comienza el año de fiestas, ellas tienen todo el aspecto de ceñirse al esquema de la "prueba calificante": los hombres instalan a los dioses (los "hacen ser"), les imponen el contrato implícito y empiezan a seducirlos con demostraciones de sumisión, de devoción y de homenaje (todo ello bajo el manto de la forma católica asimilada.) Pero ello es, al mismo tiempo, para los hombres, adquirir la competencia necesaria para el desempeño de la acción: hacer esa semana o más de fiestas es, realmente, una prueba "cierta" (ya no simulada), que implica un enorme esfuerzo económico y de trabajo, particularmente para los "pasantes" de cada fiesta.

Dentro de esta perspectiva, el Carnaval corresponde a la "prueba decisiva": es el momento culminante en la ejecución del programa. Y, en efecto, hemos visto, el Carnaval es la fiesta que tiene más 
intensidad en el calendario: en esta fiesta, "todo es como si" se jugara ahí una situación de conflicto, de lucha, de peligro, de la que depende el éxito. Todo ocurre "como si" el Supay fuera la entidad más peligrosa y difícil de conquistar (el antisujeto). Sin embargo, después de Tentación, al Supay se le despide prácticamente con viento fresco... Como se ha hecho con las almas.

Por último, Pascua, con la restauración del orden y la tranquilidad, equivale de hecho al momento de la sanción; pero es una sanción implícita, que no ha sucedido en realidad, no ha sido representada: es "como si" los hombres hubieran salido victoriosos de esta acción y obtuvieran el reconocimiento merecido. Con Pascua termina el simulacro de una acción que sólo ha servido de base para lo que verdaderamente interesa: instalar las diversas significaciones del año con las representaciones diferentes de los dioses que objetivan esas significaciones. Y, de manera llamativa, "todo ocurre como si" después de Pascua ya nada importara, como si ya no hubiera programas y la acción principal hubiera sido ya representada. Es éste un hecho que no comprendo bien todavía.

Hay, pues, así, en el calendario de fiestas, al menos en la primera mitad, todo un despliegue de programas aparentes: un programa general de conjunción/disyunción con los dioses, un programa (previo) de hacer ser a los dioses, y un programa manipulatorio con intercambio de valores. Ellos constituirían la base para "significar el tiempo". Pero admito que no comprendo bien aún de qué manera este "significar el tiempo" se puede entender más adecuadamente como programa narrativo. Admito también la falta de precisión en la formulación de los programas simulados.

Conviene destacar aquí dos hechos semióticos imponentes: primero, que siendo toda la acción del calendario una serie de programas aparentes, como se ha dicho, el desarrollo de esta acción es "esquemático": sólo se ejecutan, por decirlo así, los "puntos clave" del esquema, sin preocuparse demasiado por la fidelidad a una verdad de la construcción semiótica y de la representación "teatral". Segundo, que toda la serie de programas está referida a un inventario de supuestos "virtuales", que no se realizan: se dan por entendidos. La expresión reiterada de "todo ocurre como si" señala la referencia inevitable a esos supuestos que están "en la cabeza" de la gente (son inmanentes).
Son en buena medida estos "juegos de la verdad" los que conducen a la percepción de que el discurso religioso andino se mantiene siempre a medio filo entre el "creer" y el "no creer". Es un "hacer como si creyeran en la verdad de los dioses", pero "sin creer plenamente", oscilando entre la probabilidad y la improbabilidad de la verdad de los dioses.

Esto lo veremos mejor con lo que ocurre en Carnavales. Tomamos esta festividad para examinar el problema del creer/no creer (modalizaciones epistémicas), porque es la que mejor conocemos: no sabemos aún cómo estas modalizaciones se dan en las otras fiestas del calendario.

\section{Música y Carnaval: La vacilación epistémica del humor}

La fiesta de Carnaval se produce, ya hemos dicho, dentro de la serie de programas supuestos, particularmente dentro del programa de manipular a los dioses para obtener de ellos la fertilidad agrícola. En este caso, se trata de seducir al Supay para que otorgue -tal como otorga la música a los instrumentos- 1a abundancia en los cultivos, siendo como es la figura máxima del poder genésico y creacional. ${ }^{7}$ Pero ocurre que en este "hacer como si" sedujeran al Supay, la gente se ve envuelta en la simulación y se ve arrastrada a "vivir el Carnaval" con pasión y entrega. Y es aquí donde pienso que la música juega su papel principal.

Desde ya, la proximidad del Carnaval es esperada con excitación. Una mujer dice:

"Después de Todos Santos algunos tocan erqe y así nos apuran a hilar, a torcer el hilo, y se nos empieza a quitar el sueño. Si no hubiera Carnaval estaríamos como dormidos siempre. Los hombres nos ayudan a hilar y a torcer, todos se apuran” (R. Martínez s/f Ms).

Y otra entrevistada señala:

"Erqe es más ch'uyita (claro) y reúne a la gente. Para Carnaval, cuando tocan el erqe dicen: 'jahí está, ahí está el Carnaval!'” (R. Martínez s/f Ms).

\footnotetext{
7 De alguna manera sospecho que el ch'allaku a los instrumentos es una especie de modelo en el tratamiento del Saxra-Supay.
} 
Y es que la música de Carnaval tiene un efecto casi embriagador, produce "tentación" -al Diablo le dan también el nombre de Tentación- y pérdida de sí mismo:

"La música de Carnaval tienta. Al tentar, la música hacer llevar, perderse. Dicen que se va por una pampa y se va a las rocas. Escucho erqe y me hace doler el corazón. Vas a ese lugar y sigue... te hace llegar a cualquier roca y alli te puedes morir.. Sacamos a uno de la roca, se había hecho tentar, q'ala, pelado estaba, agonizando en una bajada de la roca” (R. Martínez s/f Ms).

El efecto tiene ciertamente implicaciones eróticas mortales, bien propias de lo demoníaco:

"Los días de Carnaval no hay que pensar en su enamorado, porque el Supay puede tentar y aparecerse con la figura del enamorado. Entonces nosotros iríamos y escucharíamos el erqe que está tocando el esposo sin poderlo ver. $O$ si se hace tentar con los Supay, se los lleva por donde sea, hasta sobre los árboles se los lleva, hasta matarlos. El ladrido de los perros evita que el Supay lleve” (R. Martínez s/f Ms).

Pero la música del Supay tiene ese efecto no sólo sobre la gente sino sobre el Supay mismo: a éste, se dice, "le fascina la música", de erqe, de thurumi, y de charango. De manera que si alguien toca muy bien, fuera de Carnavales, es peligroso, porque "tienta" al Supay y lo hace venir. Es pues, un arma de doble filo: la gente tienta al Supay con su propia música -es parte de la seducción-, pero a la vez es tentada por ésta.

Se comprende, entonces, que, en el "pensamiento" de la gente, sea en extremo peligroso este trato que se produce en Carnavales con esta deidad: la gente arriesga "perderse a sí misma", se bordea la locura. Que es lo mismo que ocurre con el ch'allaku a los instrumentos. Un programa de manipulación al Supay, que empieza siendo simulado, puede terminar, teóricamente, en una destrucción real. Pero la música domina y la gente se siente arrastrada a vivir con pasión el Carnaval. Y esto no es nada simulado. Lo que sí es simulado es el programa de seducción al Supay: el supuesto de que el Supay llega, el supuesto de que se lo atrae con bella música, con trajes de colores y luces fascinantes, de que se le rinde devoción en tomo a la pukara y en el ch'allaku a las chacras, pidiéndole abundancia. Pero la entrega y el temor van en serio.

Sin embargo, a pesar de esta parte de "verdad", el discurso verbal sobre del Supay es un discurso a medias entre el temor y el humor. Una señora entrevistada, que en una cita anterior ha destacado lo aterrante del Supay, dice lo siguiente:

"Ellos (los hombres Supay) parten para jueves de Compadres y ya llegan por acá para jueves de Comadres. Vienen desde lejos, desde donde existen los versos para cantar el Carnaval. Vienen de lugares con agua y rocas. Los hombres Supay le dicen a sus señoras: 'hila, teje, así seguro te voy a llevar'. Pero el día de Compadres desaparecen de sus señoras, sin avisarse vienen. Si vendrían sus mujeres más, los hombres correrían el riesgo de ser encantados por las mujeres(...). Para Carnaval peleamos todos: ojos en tinta, agujereada la cabeza, piernas torcidas. y de la misma forma el Supay se va, colgando sus cuernos, rotos sus pies, con chichones en su cabeza... se va con el erqe colgando, lleno de deudas, sin plata, pobre... juna pena! (...) El Supay se va domingo en la noche. Cuando llegan así, una lástima, sus mujeres se alegran. 'Ya ves', diciendo..." (R. Martínez s/f Ms).

Y algo semejante ocurre con la representación actuada: a pesar de la vena "en serio" con la que la gente se entrega al Carnaval, el domingo en la noche, culminación del caos en que ha caído la comunidad, de pronto se produce un quiebre: ocurre la "despedida" al Supay (la kacharpaya), y la deidad es echada de la comunidad jocosamente, irreverentemente: una pareja de viejos, pobremente vestidos, que se van rengueando.

¿"Creen", pues, los jalq'a en el Supay, o "no creen"? Si dijéramos "no creen", ¿cómo entender, entonces, la entrega al Carnaval, la "tentación" y el miedo al Supay, que son reales? Si dijéramos "creen" ¿cómo entender el trabajo burlesco e irreverente al Supay, en la despedida? Y este mismo quiebre se produce, ya lo hemos dicho, con las almas y en diversos otros rituales, que terminan con humor y jocosidad (rasgo no solamente jalq'a, sino "andino", hasta donde vemos).

De ahí que, hemos señalado, el discurso religioso andino se mantiene siempre a medio filo entre el "creer" y el "no creer". Todo éste es un tema de 
enorme importancia (el tema de la modalización veridictoria y epistémica del discurso religioso), que no podemos tratar aquí con detención. Tampoco tengo aún respuestas bien seguras y meditadas. Yo tengo la impresión de que en el comportamiento ritual y actuado en el Carnaval, dentro del simulacro semiótico que son todos los programas, está presente aquel programa de conjunciones y disyunciones, por parte de la gente, con la deidad; programa peligroso, que amenaza pasar de la simulación a la verdad. Y pienso que la ruptura -nueva hipótesis- mediante la jocosidad, de la vertiente "seria" (la entrega a la "tentación") es una realización "en escena", de la modalización de la creencia/no creencia en los dioses. Una realización actuada que, justamente, "salva" a la gente de los "peligros del alma". Y que, por lo mismo, permite realizar el propósito verdadero de "significar el tiempo", ya que instalar en este período del año una objetivación del "tiempo del Saxra" implica "vivir" en sí mismo el "tiempo del Saxra": instalar una objetivación en el tiempo es instalarla en la propia persona, en su vivencia interior, ya que "en el tiempo" no tiene objetividad ni permanencia (como sí ocurre con el espacio).

Pero, es claro, una hipótesis así sólo será valida cuando entendamos qué de esto se da en los otros períodos del calendario. Una explicación así parece plausible en Todos Santos y en las Alma Fiesta ya que, sabemos, las almas producen un gran temor. Pero ¿qué pasa en las fiestas del "tiempo del Saxra femenino"? (Santa Bárbara y las otras santas, de diciembre/febrero?) ¿Y qué pasa en Pascua, donde su sentido de "vuelta al orden y a la tranquilidad" no representa peligro y no solicita un recurso de protección, a pesar de lo cual también en Pascua está presente el creer/no-creer? De cualquier manera parece estar claro que en definitiva, el creer/no creer implica por encima de todo un juicio epistémico sobre el propio discurso creador de dioses. El discurso religioso andino no es un discurso de fe. ${ }^{8}$

8 Adviértase que es un creer/no creer sobre las propias creaciones: los dioses son creados por el enunciador colectivo que es una cultura andina. Por lo tanto, el discurso religioso andino -en sus diversas manifestaciones- implica un juicio epistémico del enunciador/enunciatario sobre sus propios enunciados. Lo que, como dijimos, hace de este discurso un discurso intelectual, y no un discurso de fe. Creo que aquí está, justamente, la diferencia entre el cristianismo popular latinoamericano y la religión indígena andina.
Es así, en todo este complejo proceso de creación de significaciones que comprometen vivencias espirituales en donde la música interviene de manera íntima y consustancial. La música interviene en los programas narrativos mismos, como un componte decisivo de ellos. En Carnaval, la música "es el Saxra": ella lo define y lo adjetiva. $\mathrm{Y}$ es ella la que produce ese proceso espiritual de "entregarse al Carnaval" y de pérdida de sí mismo en las personas. Por lo tanto, es la música también la que permite cumplir el propósito de "significar el tiempo" como una vivencia interior.

Me pregunto, sin embargo, si hay un "cambio" en la música de Carnaval con la ruptura de la kacharpaya, que yo, como no musicólogo, no sabría identificar ni percibir. Cuesta creer que la "misma" música induzca el proceso de una entrega peligrosa (la parte "en serio") y no haya alguna clase de cambio para subrayar el sentido jocoso y burlón de la despedida al Supay. Porque, si hay este cambio, resultaría entonces que "también la música" estaría objetivando esa vacilación epistémica de la gente entre el creer y el no-creer.

\section{Música, tejidos, discurso religioso e identidad étnica}

Un panorama así, de interdigitación tan íntima entre la música y el discurso religioso tal como se da en el calendario de fiestas, no ocurre con los tejidos. Fuera de las alusiones que hemos visto en el discurso sobre el Supay, al apuro en hilar y tejer de las mujeres, ante la llegada del Carnaval, fuera de las alusiones al engaño de sus mujeres que hacen los Saxra-Supay, prometiéndoles llevarlas a la fiesta si hilan y tejen, no parece haber otras referencias al tejido que nos permitan conectar calendario de fiestas y tejido.

Es cierto que el tema no ha sido todavía detenidamente investigado. $\mathrm{Y}$ es cierto que en el calendario del lenguaje plástico-textil tiene una presencia importante en los disfraces y vestuario de las fiestas; también en algunos objetos, todo lo cual tampoco ha sido aún investigado. Pero, por otra parte, estamos comparando dos magnitudes semióticas distintas: la relación de la música con el discurso religioso "en el calendario de fiestas" (y no fuera de éste, adviértase) es una relación de intersemióticas que producen una semiótica sincrética: un todo de significación realizado me- 
diante diversas semióticas con distintas sustancias de la expresión (aquí sí que entrarían los lenguajes plástico-textiles de los trajes de fiesta). Pero una puesta en relación de los textiles "tal como se tejen normalmente" con el discurso religioso es un hecho de intertextualidad de semióticas distintas. Lo mismo ocurriría en una relación de la música con el discurso religioso, si la tomáramos al margen del calendario.

Así planteado, es válido de todos modos preguntarse por estas relaciones. Avanzando algunos acercamientos, es evidente que el lenguaje plástico-textil, el arte de los tejidos, es una semiótica en sí, independiente, pero que toma y realiza por su cuenta significaciones que le son suministradas por el discurso religioso. Ya he hemos visto cómo los tejidos realizan la significación de Creación y Desorden definitoria de la identidad jalq'a, con su propia sustancia y forma de la expresión, y en relación con los códigos textiles andinos. Se tendría la impresión de que el discurso plásticotextil toma las estructuras de base y las tematizaciones de los significados, ofrecidas por el discurso religioso, y las actorializa según sus propias estructuras figurativas y códigos plásticos. Pero fuera de esto, yo no podría, por el momento, decir más.
Parece, pues, claro, que el discurso religioso se coloca en un nivel jerárquico superior (hipertáctico), con respecto al lenguaje textil y al lenguaje musical; define una estructura fundamental de contenidos semánticos, un microuniverso semántico de base, tematizaciones ya semielaboradas en estructuras narrativas, dejando a la música y al tejido el cuidado de figurativizar los contenidos en sus propios términos, sin obstaculizar sus propios recorridos de significación. Con lo cual el discurso religioso se ve, de vuelta, enormemente enriquecido ("en la cabeza de la gente", es decir, de un mismo enunciador de los tres discursos), no sólo en expresiones que él no podría plasmar, sino en formulaciones más precisas y vastas de sus contenidos.

Ahora, si estamos de acuerdo en que la identidad jalq'a se define -a nivel de pensamiento- como la adopción de una posición semántica en la estructura fundamental del epistema que hemos estado manejando, y esta posición es una definición "Saxra", resulta claro que, tanto el discurso religioso como la música y los tejidos, realizan -cada uno en su propio campo- esta identidad. Pero, desde luego, sólo un análisis fino de estos lenguajes connotativos y de los procedimientos semióticos podrá decirnos más adelante de qué manera concreta se construye esta identidad.

\section{REFERENCIAS CITADAS}

BOUYSSE-CASSAGNE, T., y O. HARRIS, 1987. Pacha: En torno al pensamiento aymara. En Tres reflexiones sobre el pensamiento andino, J. Medina (Ed.), pp. 11-59. Biblioteca Andina, Hisbol, La Paz.

CERECEDA, V., 1982 Ms. Notas de campo.

FIRESTONE, H., 1988. Pachamama en la cultura andina. Los Amigos del Libro, Cochabamba.

GISBERT, T., 1980. Iconografía y mitos indígenas en el arte. Gisbert y Cía., La Paz.

HARRIS, O., 1983. Los muertos y los diablos entre los laymi de Bolivia. Chungara 11: 135-152.
MARTINEZ, G., 1983. Los dioses de los cerros de los Andes. Journal de la Societé des Américanistes 69: 85-115.

MARTINEZ, R., s/f Ms. Notas de campo.

PLATT, T., 1983. Conciencia andina y conciencia proletaria: Qhuna runa y ayllu en el norte de Potosí. HISLA 2, Lima.

ROEL PINEDA, J., 1966. Creencias y prácticas religiosas en la Provincia de Chumbivilcas. En Historia y cultura. Tres estudios, pp. 28-29. Publicaciones del Museo Nacional de Historia, Lima. 